\title{
Mechanisms of action and adverse effects of the major therapeutic agents in trial for COVID-19 therapeutics: Review of literature
}

\author{
Emeka Donald Ogiji, ${ }^{1}$ Obumneme Benaiah Ezeanosike, ${ }^{1,2}$ Casimir C. Ofor, ${ }^{1}$ Edak Ezeanosike, ${ }^{3}$ \\ Charles C. Maduba, ${ }^{4}$ Samuel Ghasi ${ }^{1,5}$ \\ ${ }^{1}$ Department of Pharmacology/Therapeutics, Ebonyi State University, Abakaliki, Ebonyi State; ${ }^{2}$ Department \\ of Paediatrics, Alex-Ekwueme Federal University Teaching Hospital, Abakaliki, Ebonyi State; ${ }^{3}$ Department \\ of Ophthalmology; ${ }^{4}$ Division of Plastic Surgery, Department of Surgery, Alex-Ekwueme Federal University \\ Teaching Hospital, Abakaliki, Ebonyi State; ${ }^{5}$ Department of Pharmacology and Therapeutics, College of \\ Medicine, University of Nigeria, Enugu, Nigeria
}

\begin{abstract}
The race to find an effective cure for COVID-19 is on. Most of the candidate drugs in various clinical trials are being re-purposed but none has been approved as at date. It is pertinent for the bedside physicians to understand the mechanisms of action of these agents and their peculiar adverse effects so they are properly guided on the risk/benefit of the drugs they choose in managing
\end{abstract}

Correspondence: Emeka Donald Ogiji, Department of Pharmacology/Therapeutics, Ebonyi State University, PMB 053, Abakaliki, Ebonyi State, Nigeria.

Tel.: +234.806.515.5272

E-mail: ogijiemeka@gmail.com

Key words: COVID-19, therapeutics, clinical trials, repurposing, mechanisms of action, adverse effects.

Contributions: We declare that this work was done by the authors named in this article and all liabilities pertaining to claims relating to the content of this article will be borne by the authors. EDO, CCO and OBE conceptualised and designed the work. EDO, CCO, OBE, CCM drafted the manuscript. EE and SG critically reviewed the draft manuscript for intellectual content. All the co-authors read and approved the final draft for submission.

Conflict of interest: The authors declare no conflict of interest.

Availability of data and materials: All data generated or analyzed during this study are included in this published article.

Ethics approval and consent to participate: Not applicable.

Informed consent: Not applicable.

Received for publication: 3 November 2020

Revision received: 14 May 2021

Accepted for publication: 14 May 2021.

This work is licensed under a Creative Commons Attribution NonCommercial 4.0 License (CC BY-NC 4.0).

${ }^{\circ}$ Copyright: the Author(s), 2021

Licensee PAGEPress, Italy

Annals of Clinical and Biomedical Research 2021; 2:118

doi:10.4081/acbr.2021.118
COVID-19 patients. Clinicaltrials.gov, the international clinical trials platform of the WHO, the EU clinical trials register and the Cochrane Central Register of Controlled Trials were searched for registered clinical trials. Studies in therapeutic trials were considered eligible for the work. Frequency table was made for the most common trialled drugs and the mechanisms of actions and adverse effects of the selected drugs were reviewed. Ten studies were selected for review in a descending order of their frequency in different therapeutic trials and these are ritonavir, lopinavir, chloroquine/hydroxychloroquine, interferon, remdesvir, favipravir, umifenovir, darunavir, tocilizumab and methylprednisolone. The bedside physicians need to understand the mechanisms of action of these agents and their peculiar adverse effects for proper guidance on the risk/benefit of the drugs they choose in managing COVID19 patients.

\section{Introduction}

Coronavirus disease 2019 (COVID-19), an infectious viral disease caused by severe acute respiratory syndrome coronavirus 2 (SARS-CoV-2) was first reported in Wuhan in the Hubei province of China in December 2019. ${ }^{1}$ It was declared a public health emergency of international concern and subsequently a global pandemic by World Health Organisation on 20th January 2020 and $11^{\text {th }}$ March 2020 respectively. ${ }^{2}$ As at $17^{\text {th }}$ May 2020, there were about 4.5 million confirmed cases of COVID-19 and well over 300000 deaths resulting from the pandemic globally. ${ }^{3}$

Most of the cases of COVID-19 (about 80\%) are asymptomatic. ${ }^{4}$ In the initial symptomatic phase of the disease, there could be flu-like clinical features like sore throat, dry cough, rhinorrhea, fever and fatigue. Myalgia, shortness of breath, haemoptysis, chest pain, diarrhea, nausea and vomiting, headache and confusion may set in subsequently. In the later phase, complications like Acute Respiratory Distress Syndrome (ARDS), pneumonia, arrhythmia and septic shock may set in..$^{5-8}$ It has also been observed that the symptoms are usually more severe in elderly patients with co-morbidities, in patients with allergic conditions like asthma, and patients with Chronic Obstructive Pulmonary Disease (COPD). ${ }^{9}$

As at date, neither drug nor vaccine has been approved for the treatment or prevention of this dreaded pandemic that has plunged the entire world into confusion and fear as well as socio-economic straits. However, a combination of oxygen therapy, mechanical ventilation, drugs like antivirals, antibiotics and other supportive therapies appear to give promising clinical outcomes in the management of COVID-19 patients. ${ }^{8}$ These therapeutic agents are being used on "off-label" basis as they have not been approved for 
use in COVID-19 patients. This "off-label" use is a way of drug repurposing (drug repositioning) in the bid to find fast-tracked remedy for the disease. Drug repurposing can be said to be the process of identifying and developing new uses for existing drugs. ${ }^{10}$

A recent study shows that as at $20^{\text {th }}$ March 2020, about 344 interventional studies had been registered on clinical trials registries including ClinicalTrials.gov, WHO ICTRP, EU Clinical Trials Register, and Cochrane Central Register of Controlled Trials. ${ }^{11}$ Also, WHO had on $18^{\text {th }}$ March 2020 launched a clinical trial called SOLIDARITY to trial the four most promising drug candidates for COVID-19 treatment, namely: chloroquine/hydroxychloroquine, remdesvir, lopinavir/ritonavir and lopinavir/ritonavir/interferon beta-1a. This mega clinical trial is involving participants across over 90 countries. ${ }^{12}$ Also, as at $14^{\text {th }}$ April 2020, over 600 clinical trials on this subject matter had been registered with the WHO with about 133 of them being for therapeutic purposes. ${ }^{12}$ Putting the therapeutic drug candidates together, they fall into about four major therapeutic groups: antivirals, antimalarials, immunosuppressants/immunomodulators and antibiotics. The antiviral candidates include remdesvir, favipiravir, lopinavir/ritonavir, ostelmavir, ganciclovir, peniclovir, umifenovir, triazavirin, baloxavir marboxil, danoprevir/ritonavir, azvudine, sofosbuvir/ledipasvir, sofosbuvir/daclatasvir, darunavir/cobicistat, emtricitabine/tenofovir and ribavarin. The antibiotics include azithromycin, pirfenidone, carimycin and teicoplanin. The antimalarials are the chloroquine/hydroxychloroquine whereas the immunosuppressants/immunomodulators include glucocorticoids (corticosteroids, methylprednisolone, dexamethasone), anticytokines (tocilizumab, adalimumab, eculizumab, sarilumab, ixek- izumab) pegylated interferon with ribavarin, lopinavir/ritonavir/interferon beta-1a. ${ }^{11,12}$ This list is not exhaustive but enough to show that the race to find effective therapeutics for COVID-19 is certainly on and hopefully, some of these drug candidates will make it through the clinical trials and get formal approval.

\section{Objectives}

i) To review the mechanisms of action of the major drugs in clinical trials for COVID-19 therapeutics and ii) To highlight some of major adverse effects of these drugs to properly guide the moment-by-moment decision making of the front-line physicians.

\section{Materials and Methods}

We identified records of trials from online registries including Clinicaltrials.gov, the International clinical trials platform of the WHO, the EU clinical trials register and the Cochrane Central Register of Controlled Trials. We collated all registered trials and identified interventional studies focusing on therapeutic strategies. This identified 1835 studies. After removing duplicates, we had 915 studies from where we selected 490 that focused on therapeutic interventions having further removed studies on preventative interventions and vaccine trials. Another 150 studies were removed which was based on Chinese traditional and complementary interventions, leaving a total of 228 studies from where we selected the 10 most drugs studies which was tested in 170 trials as shown in the PRISMA flow diagram (Figure 1).

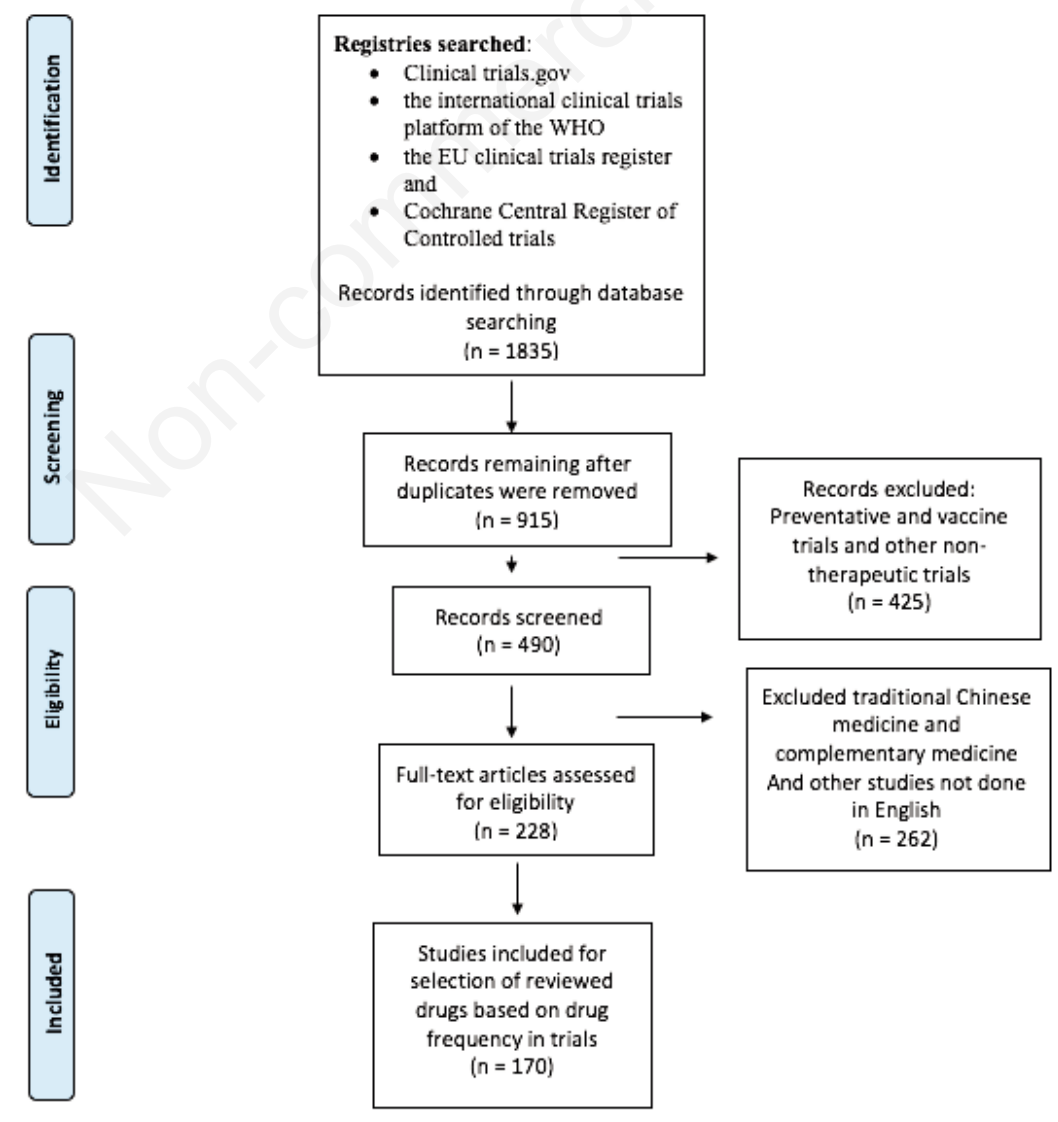

Figure 1. PRISMA flow diagram showing how the drug candidates were selected. 


\section{Data extraction}

Data extraction was done using an excel spreadsheet developed for the purpose. We collected data on the trial registration, year/month of commencement, registration body, the status of the trial, type of study (vaccine trial/therapeutic trial), and the candidate drugs. We collated only the agents in the different trials and analysed them in the frequency table shown in Appendix 1 to show the most common drugs under investigation across different trials.

\section{Results}

Figure 2 shows a graph frequency of the drugs that are in the therapeutic trials while Table 1 shows the selected drugs that featured in at least 5 trials. The ten drugs are being investigated in 170 trials either independently or in combination.

\section{Discussion}

\section{Major therapeutics in clinical trials for COVID-19 treatment}

The summary of the mechanisms of action and adverse effects of the major drugs in the trials for COVID-19 is as shown in Table 2.

\section{Antivirals}

\section{Lopinavir/Ritonavir}

Lopinavir and ritonavir are protease inhibitors approved for use in Human Immunodeficiency Virus (HIV) 1. They are among the drugs being trialled for possible repurposing in COVID-19 treatment. Lopinavir/ritonavir is usually given as a combination therapy as ritonavir is said to increase the half-life of lopinavir by inhibiting the cytochrome P450 that metabolises it. Protease inhibitors generally prevent maturation of the viral particles by binding to the HIV-1 protease enzyme and preventing the cleavage of Gag-pol polyproteins (group-specific antigen-polymerase). This leads to the production of nascent immature, defective viral particles that are non-infectious. ${ }^{5,13-16}$

Lopinavir/ritonavir are used as combination drugs in the treatment of Human Immunodeficiency Virus-1 (HIV-1). Ritonavir increases the half-life of lopinavir by inhibiting cytochrome P450. ${ }^{15}$

Table 1. The most common drugs under investigation across different trials and selected drugs which featured in at least 5 trials.

\begin{tabular}{lcc} 
S/N & Drug candidate & Number of trials \\
1 & Ritonavir & 38 \\
2. & Lopinavir & 34 \\
\hline 3 & Chloroquine/hydroxychloroquine & 31 \\
4 & Interferon alpha & 22 \\
\hline 5 & Remdesvir & 10 \\
6 & Favipravir & 9 \\
\hline 7 & Umifenovir & 9 \\
8 & Darunavir & 6 \\
\hline 9 & Tocilizumab & 6 \\
10 & Methylprednisolone & 5 \\
\hline
\end{tabular}

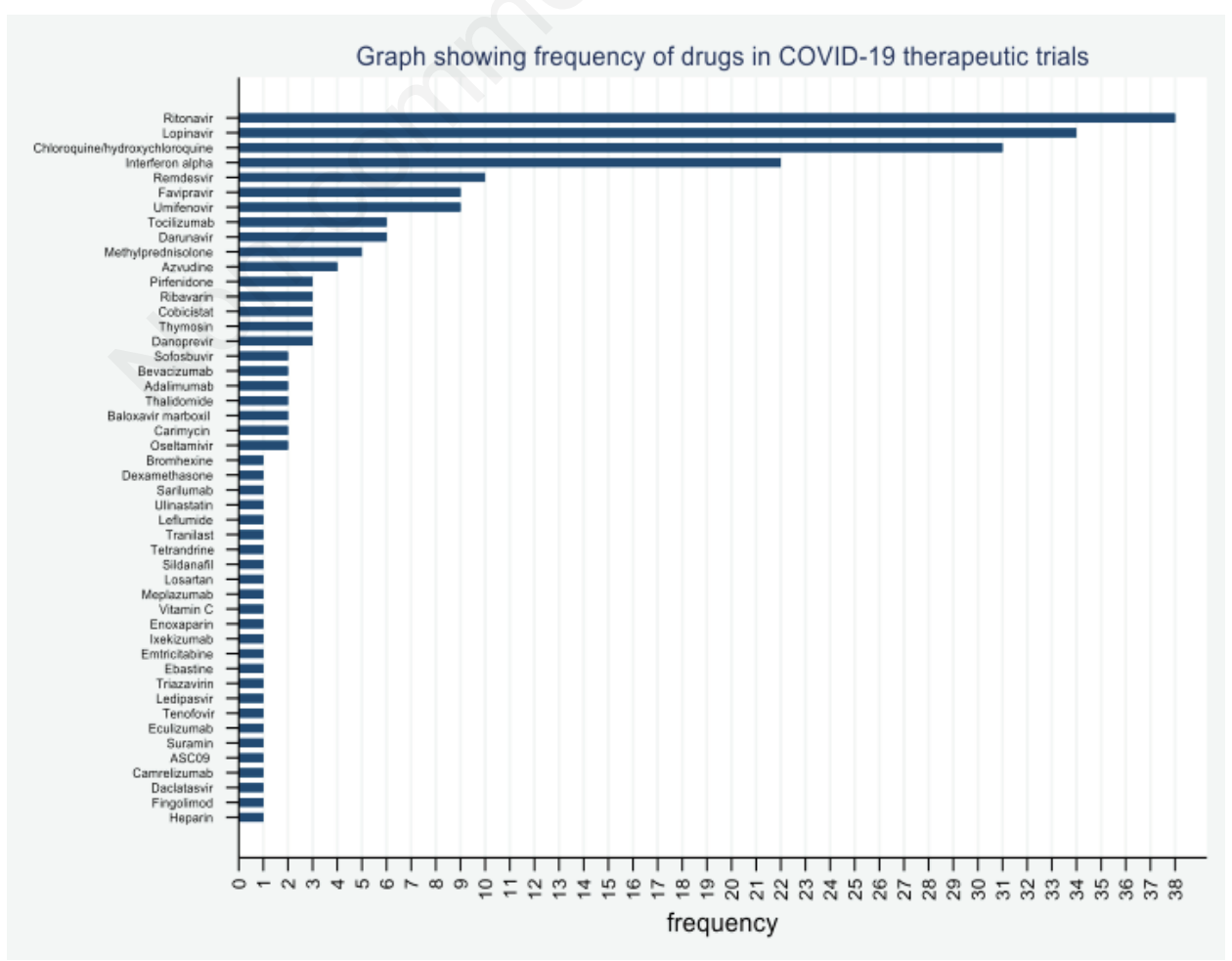

Figure 2. Frequency of drugs currently in COVID-19 therapeutic trials. 
Table 2. Summary of the mechanisms of action and adverse effects of the major drugs in trial for COVID-19.

\begin{tabular}{|c|c|c|c|c|c|}
\hline Candidate drug & Drug class & Current indication & Mechanism of action & Adverse effects & Status of clinical trials \\
\hline Lopinavir/ritonavir & $\begin{array}{l}\text { Protease inhibitors } \\
\text { (antiviral) }\end{array}$ & HIV-1 & $\begin{array}{l}\text { Inhibition of protease by } \\
\text { preventing the cleavage of } \\
\text { Gag-pol polyproteins }\end{array}$ & $\begin{array}{l}\text { Nausea and vomiting } \\
\text { Diarrheoa } \\
\text { Anemia } \\
\text { Hyperlipidaemia, } \\
\text { ALLT elevation } \\
\text { Impaired cognition/memory } \\
\text { Insomnia }\end{array}$ & $\begin{array}{l}\text { On-going for SARS and } \\
\text { COVID-19 } \\
\text { (ChiCTR2000029539) }\end{array}$ \\
\hline
\end{tabular}

\begin{tabular}{llll}
$\begin{array}{l}\text { Chloroquine/ } \\
\text { hydroxychloroquine }\end{array}$ & Antimalarials & $\begin{array}{l}\text { Malaria } \\
\text { Autoimmune diseases }\end{array}$ & $\begin{array}{l}\text { Suppression of cytokine } \\
\text { (TNF, IL, IFN) } \\
\text { production/release } \\
\text { Inhibition of viral replication. }\end{array}$ \\
& & \\
& & \\
& & \\
\hline Remdesvir & Phosphoraramidate & Under trial for Ebola & Inhibition of RdRp causing \\
& nucleotide (antiviral) & & of viral RNA transcription
\end{tabular}

\begin{tabular}{lll} 
Favipiravir & $\begin{array}{l}\text { Viral polymerase } \\
\text { inhibitior }\end{array}$ & $\begin{array}{l}\text { Influenza strains } \\
\text { unresponsive to current } \\
\text { antivirals }\end{array}$ \\
\hline Darunavir & $\begin{array}{l}\text { Viral Protease } \\
\text { inhibitor }\end{array}$ & HIV -1 Infection \\
& \\
& \\
\end{tabular}

\begin{tabular}{|c|c|c|}
\hline Umifenovir & Antiviral & Influenza \\
\hline Interferon & $\begin{array}{l}\text { Immunomodulatory } \\
\text { (Antiviral) }\end{array}$ & $\begin{array}{l}\text { Multiple sclerosis, } \\
\text { osteoporosis, } \\
\text { Hepatitis B and C virus } \\
\text { infections. } \\
\text { HPV } \\
\text { Kaposi sarcoma }\end{array}$ \\
\hline Methylprednisolone & $\begin{array}{l}\text { Anti-inflammatory. } \\
\text { Immunomodulatory }\end{array}$ & $\begin{array}{l}\text { Inflammatory conditions } \\
\text { like dermatitis, } \\
\text { Stevens-Johnson syndrome } \\
\text { Autoimmune and aplastic } \\
\text { anemias, nephrotic syndrome } \\
\text { Secondary adrenal } \\
\text { insufficiency }\end{array}$ \\
\hline
\end{tabular}

Inhibition the RdRp of influenza virus transcriptase) thereby interfering with the viral replication

\section{Inhibition of protease} by preventing the cleavage of Gag-pol polyproteins
It binds directly to influenza

haemagglutinin (HA) and

inhibit its ability to transit

0 an activated conformation.

It also impairs fusion by

intercalation into the viral

or target membrane,

thereby rendering the

membrane less yielding for fusion

activation of autophagy-

inducing kinase, AMPK

in viruses; it also activates macrophages that engulf

antigens and natural killer cells (an immune T-cells)

Binds to and activates specific

production
Gastrointestinal upset $\quad$ On-going for COVID-19

Generalized pustular rash $\quad$ [ChiCTR2000029609

Urticaria,

Erythroderma

(ICTPR);

Macular retinopathy

Cardiomyopathy

Arrhythmias

OT interval prolongation.

Dizziness

Tinnitus,

Headaches

Nightmares

Will likely emerge

EUCTR2020-001406-27-FR]

cos

In phase II clinical trial

for Ebola

(NCT03719586); (polymerase basic 1 as clinical trials unfold

In phase III clinical trials for COVID-19

(NCT04252664)

Diarhhoea

Teratogenicity

In clinical trial for

Increased serum uric

COVID-19

(ChiCTR2000029548)

acid levels

Increased levels

of transaminases

Reduced neutrophil counts

Blurred vision

Sweating

Myalgia

Constipation

Diarrhoea

Jaundice

Facial puffiness

Difficulty in breathing

Vomiting

Tachycardia

Hypersensitivity in

children

Recruiting stage of clinical

Inhibition of the

Fever

Myalgia

clinical trial

Hepatopathy

for COVID-19

Difficulty in breathing
Anaphylactic reactions

Depression

Suicidal ideation

Glaucoma

gene expression and inhibition Hypertension

of pro-inflammatory cytokine Peptic ulcer disease

Pancreatitis

Hyperglycaemia

Hypocalcaemia

Metabolic acidosis

Growth suppression

\begin{tabular}{lll}
\hline Tocilizumab & Immunomodulator & Rheumatoid arthritis \\
& Anti-inflammatory & Juvenile idiopathic arthritis
\end{tabular}

Non-infectious uveitis
Inhibition of interleukin- 6

(IL-6) binding to both

Upper respiratory tract

infections.

membrane-bound and soluble Elevated liver enzymes

receptors (IL-6R) in the system Hypercholestrolaemia

resulting in immunomodulation Gastritis

and anti-inflammation

Gastro-intestinal perforation. 
The adverse effects that have been reported with lopinavir/ritonavir include nausea and vomiting, diarrhea, anemia, hyperlipidaemia, Alanine Transaminase (ALT) elevation, impaired cognition or memory, insomnia and skin toxicity. ${ }^{13,17-19}$ It is therefore instructive to be cautious in administering lopinavir/ritonavir to patients that have impaired liver functions, dyslipidaemia and psychiatric disposition.

\section{Remdesvir}

Remdesivir is an investigational drug in trial for Ebola and COVID-19. It is a phosphoraramidate nucleotide prodrug with the chemical formula: Pyrrolo[2,1-f][triazin-4-amino] Adenine CNucleoside. It is said has broad-spectrum in vitro activity against RNA viruses like Ebola, Marburg, MERS-CoV, SARS-CoV. It becomes active after phosphorylation to a triphosphate in the host's cell. Remdesivir targets the viral RNA-dependent RNA polymerase $(\mathrm{RdRp})$, which is the complex protein the coronaviruses use for the replication of their RNA genomes. Its mechanism of action in human is not fully understood but in vitro and non-human evidence suggests that it might be that it inhibits RdRp thereby causing premature termination of viral RNA transcription process leading to termination of the overall RNA synthesis. ${ }^{15,20-23}$

A recent preliminary report from one the clinical trial groups for remdesvir suggests the drug caused $31 \%$ improvement in the days taken for the recovery of COVID-19 patients. ${ }^{24}$

However, no formal approval has been given for its use in Ebola or COVID-19 or any other disease condition.

The adverse effects of the drug will likely be emerging as the clinical trials progress.

\section{Favipravir}

This viral polymerase inhibitor is approved, in Japan, for the treatment of novel strains of the influenza virus unresponsive to current antivirals. Its activity spectrum spreads across A, B and C strains of the virus. Favipravir becomes active after ribosylation and phosphorylation. This triphosphorylated favipravir competitively inhibit the viral RNA-dependent RNA polymerase (RdRp) of influenza virus known as polymerase basic 1 transcriptase thereby interfering with the viral replication. ${ }^{25-29}$

Its therapeutic use, for now, is in the treatment of resistant strains of influenza virus. ${ }^{29}$

Favipravir is well tolerated clinically but the adverse effects that can be associated with its use include diarrhoea, teratogenicity, increased serum uric acid levels, elevated levels of transaminases, reduced neutrophil counts. . $^{25,28,29}$

\section{Darunavir}

Darunavir is a protease enzyme inhibitor with activity against HIV-1. It prevents HIV replication through binding to the enzyme, stopping the dimerization and the catalytic activity of HIV-1 protease. SARS-CoV-2 being an RNA virus also uses protease enzyme, which the drug inhibits, hence the drug is one of the antiviral candidates in clinical trial for the treatment of COVID-19.

Darunavir has bimodal activity against HIV-1 protease, enzymatic inhibition and protease dimerization inhibition. It has a high genetic barrier to the development of HIV-1 drug resistance. ${ }^{30}$

Ritonavir-boosted atazanavir/darunavir combination is approved for the treatment antiretroviral naïve patients in the United States of America. ${ }^{31}$

Adverse effects include blurred vision, sweating, increased urination, difficulty in breathing, jaundice, myalgia, facial puffiness, tachycardia, sore throat and vomiting. ${ }^{32,33}$

\section{Umifenovir}

Umifenovir is an indole-based hydrophobic dual-acting direct antiviral/host-targeting agent used for the treatment and prophylaxis of influenza and other respiratory infections. It has been in use in the treatment of influenza in China and Russia for so many years. ${ }^{34,35}$ It has been reported to have inhibitory effects on a diverse array of viruses, including DNA and RNA viruses (SARS$\mathrm{CoV}-2$ is an RNA virus) as well as capsid and membrane-enclosed viruses. ${ }^{34,35}$ Umifenovir inhibits the entry of the influenza virus at the late stage by binding directly to influenza Haemagglutinin (HA) and inhibiting its ability to transit to an activated conformation. It also impairs fusion by intercalation into the viral or target membrane, thereby rendering the membrane less yielding for fusion. Umifenovir is used therapeutically for the prophylaxis and treatment of influenza and other respiratory infections. ${ }^{34,35}$ Major adverse effect is hypersensitivity in children. It is administered orally with an elimination half life of 17-21 hours. ${ }^{34,36}$

\section{Antimalarials}

\section{Chloroquine/hydroxychloroquine (CQ/HCQ)}

Chloroquine, a 9-aminoquinolne, has been in clinical use since the $20^{\text {th }}$ century. Hydroxychloroquine is the hydroxylated (and safer) form of chloroquine. CQ/HCQ was approved for the treatment of malaria and autoimmune disorders like rheumatoid arthritis, systemic lupus erythematosus, Sjögren syndrome, etc. Its antimalarial use has been largely suspended due to resistance. ${ }^{37-42}$

$\mathrm{CQ} / \mathrm{HCQ}$ also has interesting antiviral activities and strong immunomodulatory effects that have led to robust scientific discussions that have culminated to several trials for possible approval for treatment of emerging viral diseases like SARS-CoV2. Its immunomodulatory effect occurs by the suppression of Tcells production/release of the cytokines - tumour necrosis alpha (TNF- $\alpha$ ), the interleukins (IL 1, 2, 6 or 18) and interferon alpha and gamma (IFN- $\alpha, \gamma)$ which mediate the inflammatory complications of several viral diseases especially in COVID-19.

CQ/HCQ inhibits viral replication in many ways: i) inhibition of the pre-entry step of the viral cycle by interfering with viral particles binding to their cellular cell surface, ii) impairment of the early stage of virus replication by interfering with the $\mathrm{pH}$-dependent endosome-mediated viral entry of susceptible viruses (like flaviviruses, retroviruses, and coronaviruses) by increasing both the endosomal and lysosomal $\mathrm{pH}$ leading to non-fusion with the host cell, iii) interference with the post-translational modification of the viral proteins thereby making the nascent viral particles noninfectious. ${ }^{37-42}$

The FDA approved CQ/HCQ include treatment of malaria (except resistant $P$. falciparum and $P$. vivax causing malaria), rheumatic disease, discoid and systemic lupus erythematosus, rheumatoid arthritis and Sjögren syndrome. ${ }^{38}$

Adverse effects are rarely seen with CQ/HCQ use. However, there could be gastrointestinal upset and hypersensitivity skin reactions (generalized pustular rash, urticaria, erythroderma). There are also chances of macular retinopathy, cardiomyopathy, arrhythmias, QT interval prolongation. There could also be dizziness, tinnitus, headaches and nightmares. ${ }^{39,40}$

\section{Immunosuppressants/immunomodulators}

\section{Interferons}

Interferons are proteins that can induce a non-specific resistance to viral infections by several mechanisms, including the inhibition of protein synthesis, inactivation of viral RNA, and enhancement of phagocytic and cytotoxic mechanisms. ${ }^{43}$ The Interferon (IFN) system represents the first line of defence against 
a wide range of viruses (in this instance, SARS-CoV-2). Viral infection rapidly triggers the transcriptional induction of IFN- $\beta$ and IFN-Stimulated Genes (ISGs), whose protein products act as viral restriction factors by interfering with specific stages of the virus life cycle, such as entry, transcription, translation, genome replication, assembly and egress. ${ }^{44,45}$

Interferons activate macrophages that engulf antigens and Natural Killer cells (NK cells), a type of immune T-cells that are integral in the innate immune system.

The therapeutic uses of interferons include treatment of hepatitis $\mathrm{B}$ and $\mathrm{C}$ virus infection, haematological cancers, cervical cancer, anogenital malignancies, Kaposi sarcoma, chronic granulomatous disease and osteoporosis. They have also been found effective in treating asthmatic exacerbations caused by viral infection. ${ }^{46}$

Adverse effects include, fever, myalgia, confusion, leucopenia, elevated liver enzymes. ${ }^{44,47}$

\section{Methylprednisolone}

Methylprednisolone is a synthetic corticosteroid with inflammatory and immunomodulating properties which could be beneficial in reducing the massive inflammatory response that SARS$\mathrm{CoV}-2$ induces. It binds to and activates specific nuclear receptors, which have $\alpha$ and $\beta$ isoforms. The complex formed binds to specific Glucocorticoid Response Elements (GREs) resulting in altered gene expression and inhibition of pro-inflammatory and cytokine production. This agent also decreases the number of circulating lymphocytes, induces cell differentiation and stimulates apoptosis in sensitive tumour cell populations thereby increasing survival and accumulation of neutrophils at inflammatory sites as well as induction of basophil apoptosis. ${ }^{48-50}$

Methylprednisolone is used therapeutically in a myriad of inflammatory conditions such as dermatitis, pemphigus vulgaris, bullous pemphigus, erythema multiforme, Stevens-Johnson syndrome/toxic epidermal necrolysis, inflammatory bowel disease, multiple sclerosis, uveitis, scleritis, chorioretinitis, iritis and iridocyclitis, keratitis, optic neuritis, retinal vasculitis, and allergic conjunctivitis. It is also used to treat nephrotic syndrome and some inflammatory respiratory diseases, acute rheumatic carditis, acute gout, ankylosing spondylitis, dermatomyositis and polymyositis, psoriatic arthritis, rheumatoid arthritis, systemic lupus erythematosus as well as anaemias (autoimmune haemolytic and aplastic). ${ }^{51}$

The adverse effects are cataract, glaucoma, hypertension, pancreatitis, myopathy, osteoporosis, psychosis, hyperglycaemia, hypocalcaemia, metabolic acidosis and secondary adrenal insufficiency. ${ }^{52,53}$

\section{Tocilizumab}

Tocilizumab is a genetically-engineered monoclonal antibody humanized from a mouse antihuman Interleukin 6 (IL-6) receptor antibody. It has a broad-spectrum immunomodulatory activity. It inhibits IL-6 from binding to both membrane-bound and soluble receptors. IL- 6 is a cytokine produced by the various immune cells in response to molecular patterns and affects multi-inflammatory cells. IL-6 is involved in differentiation of CD-4 cells into Th-17 cells that play a significant role in various immune-mediated diseases. SARS-COV-2 is thought to induce massive cytokine storm, especially IL-6, therefore, the inhibition of this IL-6 by tocilizumab significantly blocks this pathway and consequent inflammatory sequelae associated with COVID-19 disease..$^{54,55}$

The clinical indications include rheumatoid arthritis, juvenile idiopathic arthritis and non-infectious uveitis. ${ }^{54,56}$

The adverse effects associated with tocilizumab include upper respiratory tract infections, elevated liver enzymes, hypercholesterolaemia, gastritis, mouth ulcers, gastrointestinal perforation. ${ }^{55}$

\section{Limitations}

COVID -19 is new. Trials are being registered and updated almost weekly, so it is impossible to give the most current status of therapeutic trials worldwide. We selected the most trialled drugs as at the time of initiation of review.

Some trials were conducted in languages other than English and were not reviewed.

The number of drugs under trials are too many and practically not feasible to review all in this context.

\section{Conclusions}

The race to find an effective cure for COVID-19 is on. Most of the candidate drugs in various clinical trials are being re-purposed but none has been approved as at date. It is pertinent for the bedside physicians to understand the mechanisms of action of these agents and their peculiar adverse effects so they are properly guided on the risk/benefit of the drugs they choose in managing COVID-19 patients.

\section{References}

1. Lu R, Zhao X, Li J, et al. Genomic characterisation and epidemiology of 2019 novel coronavirus: implications for virus origins and receptor binding. Lancet 2020;395:565-74.

2. WHO. Rolling updates on coronavirus disease (COVID-19). Geneve: WHO; 2020. Accessed: 31st July 2020. Available from: https://www.who.int/emergencies/diseases/novel-coronavirus-2019/events-as-they-happen

3. WHO. Coronavirus disease (COVID-19) Situation Report 118. Geneve: WHO; 2020. Available from: https:/www.who.int/docs/default-source/coronaviruse/situat i o n - reports / 20200517 - covid - 19 - s itre p 118.pdf?sfvrsn=21c0dafe_10

4. Crosby JC, Heimann MĀ, Burleson SL, et al. COVID-19: A review of therapeutics under investigation. J Am Coll Emerg Physicians Open 2020;1:231-7.

5. Yan Y, Shin WI, Pang YX, et al. The first 75 days of novel coronavirus (SARS-CoV-2) outbreak: recent advances, prevention, and treatment. Int $\mathrm{J}$ Environ Res Public Health 2020; $17: 30$.

6. Wang D, Hu B, Hu C, et al. Clinical characteristics of 138 hospitalized patients with 2019 novel coronavirus-infected pneumonia in Wuhan, China. JAMA 2020;323:1061-9.

7. Huang C, Wang Y, Li X, et al. Clinical features of patients infected with 2019 novel coronavirus in Wuhan, China. Lancet 2020;395:497-506.

8. Chen N, Zhou M, Dong X, et al. Epidemiological and clinical characteristics of 99 cases of 2019 novel coronavirus pneumonia in Wuhan, China: a descriptive study. Lancet 2020;395:507-13.

9. Yang X, Yu Y, Xu J, et al. Clinical course and outcomes of critically ill patients with SARS-CoV-2 pneumonia in Wuhan, China: a single-centered, retrospective, observational study. Lancet Respir Med 2020;8:475-81.

10. Ashburn TT, Thor KB. Drug repositioning: identifying and developing new uses for existing drugs. Nat Rev Drug Discov 2004;3:673-83.

11. Lythgoe MP, Middleton P. Ongoing clinical trials for the man- 
agement of the COVID-19 pandemic. Trends Pharmacol Sci 2020;41:363-82.

12. WHO. "Solidarity" clinical trial for COVID-19 treatments. Available from: https://www.who.int/emergencies/diseases/novel-coronavirus2019/global-research-on-novel-coronavirus-2019-ncov/solidarity-clinical-trial-for-covid-19-treatments

13. Dionne B. Key principles of antiretroviral pharmacology. Infect Dis Clin North Am 2019;33:787-805.

14. Paintsil E, Cheng YC. Antiviral Agents. In: Encyclopedia of Microbiology. Eds: Thomas M. Schmidt. Michigan: Elsevier; 2019: pp. 176-225.

15. Sheahan TP, Sims AC, Leist SR, et al. Comparative therapeutic efficacy of remdesivir and combination lopinavir, ritonavir, and interferon beta against MERS-CoV. Nat Commun 2020;11:222.

16. Tobaiqy M, Qashqary M, Al-Dahery S, et al. Therapeutic management of patients with COVID-19: a systematic review. Infect Prev Pract 2020;2:17.

17. Jespersen S, Hønge BL, Krarup H, et al. Protease inhibitors or NNRTIs as first-line HIV-1 treatment in West Africa (PIONA): A randomized controlled trial. J Acquir Immune Defic Syndr 2018;79:386-93.

18. Silva B, Peixoto G, da Luz S, et al. Adverse effects of chronic treatment with the Main subclasses of highly active antiretroviral therapy: a systematic review. HIV Med 2019;20:429-38.

19. Su B, Wang Y, Zhou R, et al. Efficacy and tolerability of lopinavir/ritonavir- and efavirenz-based initial antiretroviral therapy in HIV-1-infected patients in a tertiary care hospital in Beijing, China. Front Pharmacol 2019;10:1472.

20. Amirian ES, Levy JK. Current knowledge about the antivirals remdesivir (GS-5734) and GS-441524 as therapeutic options for coronaviruses. One Health 2020;9:100128.

21. Brown AJ, Won JJ, Graham RL, et al. Broad spectrum antiviral remdesivir inhibits human endemic and zoonotic deltacoronaviruses with a highly divergent RNA dependent RNA polymerase. Antiviral Res 2019;169:104541.

22. Jordan PC, Liu C, Raynaud P, et al. Initiation, extension, and termination of RNA synthesis by a paramyxovirus polymerase. PLoS Pathog 2018;14:e1006889.

23. Tchesnokov EP, Feng JY, Porter DP, Götte M. Mechanism of inhibition of Ebola virus RNA-dependent RNA polymerase by remdesivir. Viruses 2019;11:326.

24. Ledford $\mathrm{H}$. Hopes rise for coronavirus drug remdesvir. Nature 2020. doi: https://doi.org/10.1038/d41586-020-01295-8

25. Hayden FG, Shindo N. Influenza virus polymerase inhibitors in clinical development. Curr Opin Infect Dis 2019;32:176-86.

26. Beigel JH, Nam HH, Adams PL, et al. Advances in respiratory virus therapeutics - A meeting report from the 6th isirv Antiviral Group conference. Antiviral Res 2019;167:45-67.

27. Furuta Y, Gowen BB, Takahashi K, et al. Favipiravir (T-705), a novel viral RNA polymerase inhibitor. Antiviral Res 2013;100:446-54.

28. Madelain V, Nguyen TH, Olivo A, et al. Ebola virus infection: review of the pharmacokinetic and pharmacodynamic properties of drugs considered for testing in human efficacy trials. Clin Pharmacokinet 2016;55:907-23.

29. Principi N, Camilloni B, Alunno A, et al. Drugs for influenza treatment: is there significant news? Front Med (Lausanne) 2019;6:109

30. Aoki M, Das D, Hayashi H, et al. Mechanism of darunavir (DRV)'s high genetic barrier to HIV-1 resistance: A key V32I substitution in protease rarely occurs, but once it occurs, it pre- disposes HIV-1 to develop DRV resistance. mBio 2018;9:e02425-17.

31. Antoniou T, Szadkowski L, Walmsley S, et al. Comparison of atazanavir/ritonavir and darunavir/ritonavir based antiretroviral therapy for antiretroviral naïve patients. BMC Infect Dis 2017:17:266.

32. Antinori A, Rusconi S, Gianotti N, et al. Cardiovascular adverse events during treatment with darunavir-based regimens in an Italian observational study. Drug Des Devel Ther 2019;13:1667-85.

33. Delicio AM, Lajos GJ, Amaral E, et al. Adverse effects of antiretroviral therapy in pregnant women infected with HIV in Brazil from 2000 to 2015: a cohort study. BMC Infect Dis 2018;18:485.

34. Fink SL, Vojtech L, Wagoner J, et al. The antiviral drug arbidol inhibits zika virus. Sci Rep 2018;8:8989.

35. Pshenichnaya NY, Bulgakova VA, Lvov NI, et al. Clinical efficacy of umifenovir in influenza and ARVI (study ARBITR). Ter Arkh 2019;91:56-63.

36. Hulseberg CE, Fénéant L, Szymańska-de Wijs KM, et al. Arbidol and other low-molecular-weight drugs that inhibit lassa and ebola viruses. J Virol 2019;93:e02185-18.

37. Devaux CA, Rolain JM, Colson P, Raoult D. New insights on the antiviral effects of chloroquine against coronavirus: what to expect for COVID-19? Int J Antimicrob Agents 2020;55:105938.

38. Al-Bari MA. Chloroquine analogues in drug discovery: new directions of uses, mechanisms of actions and toxic manifestations from malaria to multifarious diseases. J Antimicrob Chemother 2015;70:1608-21.

39. D'Alessandro S, Scaccabarozzi D, Signorini L, et al. The use of antimalarial drugs against viral infection. Microorganisms 2020;8:85.

40. Haładyj E, Sikora M, Felis-Giemza A, M. Olesińska. Antimalarials - are they effective and safe in rheumatic diseases? Reumatologia 2018;56:164-73.

41. Savarino A, Boelaert JR, Cassone A, et al. Effects of chloroquine on viral infections: an old drug against today's diseases? Lancet Infect Dis 2003;3:722-7.

42. Sharma A. Chloroquine paradox may cause more damage than help fight COVID-19. Microbes Infect 2020;22:154-6.

43. Ozato K, Tailor P, Kubota T. The interferon regulatory factor family in host defense: mechanism of action. J Biol Chem 2007;282:20065-9.

44. O'Brien TR, Thomas DL, Jackson SS, et al. Weak induction of interferon expression by severe acute respiratory syndrome coronavirus 2 supports clinical trials of interferon- $\lambda$ to treat early coronavirus disease 2019. Clin Infect Dis 2020;71:14102.

45. Subramanian G, Kuzmanovic T, Zhang Y, et al. A new mechanism of interferon's antiviral action: Induction of autophagy, essential for paramyxovirus replication, is inhibited by the interferon stimulated gene, TDRD7. PLoS Pathog 2018;14:e1006877.

46. George PM, Badiger R, Alazawi W, et al. Pharmacology and therapeutic potential of interferons. Pharmacol Therapeutics 2012;135:44-53.

47. Prokunina-Olsson L, Alphonse N, Dickenson RE, et al. COVID-19 and emerging viral infections: The case for interferon lambda. J Exp Med 2020;217:e20200653.

48. Ferrara G, Petrillo MG, Giani T, et al. Clinical use and molecular action of corticosteroids in the pediatric age. Int J Mol Sci 2019;20:444. 
49. Ponticelli C, Locatelli F. Glucocorticoids in the treatment of glomerular diseases: pitfalls and pearls. Clin J Am Soc Nephrol 2018;13:815-22.

50. Williams DM. Clinical pharmacology of corticosteroids. Respiratory Care 2018;63:655-70.

51. Ocejo A, Correa R. Methylprednisolone. 2021 May 7. In: StatPearls [Internet]. Treasure Island (FL): StatPearls Publishing.

52. Wang Y, Jiang W, He Q, et al. A retrospective cohort study of methylprednisolone therapy in severe patients with COVID-19 pneumonia. Signal Transduct Target Ther 2020;5:57.

53. Zhou W, Liu Y, Tian D, et al. Potential benefits of precise cor- ticosteroids therapy for severe 2019-nCoV pneumonia. Signal Transduct Target Ther 2020;5:18.

54. Karkhur S, Hasanreisoglu M, Vigil E, et al. Interleukin-6 inhibition in the management of non-infectious uveitis and beyond. J Ophthalmic Inflamm Infect 2019;9:17.

55. Luo P, Liu Y, Qiu L, et al. Tocilizumab treatment in COVID19: A single center experience. J Med Virol 2020;92:814-8.

56. Oldfield V, Dhillon S, Plosker GL. Tocilizumab: a review of its use in the management of rheumatoid arthritis. Drugs 2009;69:609-32. 